\title{
News from the International Academy of Wood Science
}

\author{
Xavier Deglise
}

Published online: 15 July 2009

(C) Springer-Verlag 2009

The 2009 IAWS Conference was held in Russia at the Saint-Petersburg State Forest Technical Academy, on 15-17 June 2009 and at the Moscow State Forestry University, on 18-20 June 2009. The theme of the meeting- "Forests as a renewable source of vital values for changing world"-was partly directed at considering the situation of Russian forests, which represent the world's major reserve of wood.

A very broad range of contributions, oral and posters, mainly by representatives of government research organisations and universities was presented. There were two official languages, English and Russian with an excellent simultaneous translation allowing fruitful discussions between Russian and English speaking participants. More than 100 scientists from 20 countries discussed such diverse topics like: wood structure from nano- to macro-scales, wood as an industrial raw material, wood processing, industrial control of wood and wood products, innovative and smart wood products, sustainable use of forest resources, multiple forest values, forest resources and global wood products markets and trade, wood forming, wood plant physiology and dendrochronology, and biomechanics. 18 Fellows of the Academy from China, Finland, France, Germany, Japan, Poland, Sweden and USA attended the conference despite difficulties caused by to the global financial crisis and visa problems.

A very interesting field trip around Saint Petersburg including a visit to a modern plant producing outdoor furniture for children was organized by the Forest Technical Academy. This high performing company was managed by a young staff, including graduates and PhDs from the Forest Technical Academy.

The Academy lecture "Wood as a Natural Smart Material" was presented by Fellow Boris Ugolev, Professor at the Moscow State Forest University and President of the Regional Council of Wood Science. The audience was impressed by the excellent, clear, pedagogic scientific presentation, which gave a good overview of wood as a material for the future. It is a noteworthy and remarkable fact that Professor Ugolev is in his 64th year of research and teaching activity! 
It was the first time that an Academy event has been organized in Russia. Moscow State Forestry University is a supporting member of the Academy and both it and St Petersburg State Forest Technical Academy are keen to strengthen their relationships with IAWS. For the university in Moscow, it was its first time welcoming and organizing a meeting with participants from the west. The atmosphere was very friendly and close exchanges between participants made this 2009 IAWS Conference a real success.

Xavier Deglise

Past President of IAWS 